CLINICAL ETHICS

\title{
Ethical and professional conduct of medical students: review of current assessment measures and controversies
}

\author{
K Boon, J Turner
}

J Med Ethics 2004;30:221-226. doi: 10.1136/jme.2002.002618

As medical education increasingly acknowledges the importance of the ethical and professional conduct of practitioners, and moves towards more formal assessment of these issues, it is important to consider the evidence base which exists in this area. This article discusses literature about the health needs and problems experienced by medical practitioners as a background to a review of the current efforts in medical education to promote ethical conduct and develop mechanisms for the detection and remediation of problems.

See end of article for authors' affiliations

.....................

Correspondence to: $J$ Turner, Department of Psychiatry, University of Queensland, K Floor, Mental Health Centre Herston 4029, Australia; jane.turner@uq.edu.au

Received

25 November 2002

Revised version received

17 March 2003

Accepted for publication

2 June 2003
$\mathrm{T}$ he emphasis on knowledge, techniques, and evidence based medicine in medical education $^{1}$ is seen by some as occurring at the expense of the doctor-patient relationship. Medical education is increasingly cognisant of this issue, the promotion of interpersonal skills, professional behaviours and attitudes being stressed, ${ }^{1}$ along with increased emphasis on the personal development of medical students, including self awareness, personal growth and wellbeing. ${ }^{2}$

It is estimated that approximately $15 \%$ of physicians will be impaired at some point in their careers. ${ }^{3}$ However impairment means more than making incorrect diagnoses or failure to treat appropriately - it may also include avoidance of patients and their psychological needs, dehumanised care, inappropriate treatment, or over involvement in care. A vulnerable doctor may also be more inclined to look to patients to meet his or her own emotional needs. Although sexual exploitation is often seen as the most serious form of boundary violation, even more minor "blurring" can lead to compromised patient care. Doctors from all areas of medicine have been implicated in such boundary violations. ${ }^{4}$

About $1 \%$ of doctors abuse opiates, and up to $7-8 \%$ of doctors may have significant alcohol problems, ${ }^{5}$ with clear implications for clinical care. Although alcoholism in the profession is more evident in the older population, those who are clearly alcohol dependent have usually displayed evidence of this from their student days. ${ }^{6}$ Of concern is the traditional view that drinking is a socially acceptable discharge of stress for students, with a reluctance of other students or faculty to consider the longer term risks facing such students.

Substance abuse may also represent a flawed attempt to deal with other problems such as depression. In Canada it is estimated that $23 \%$ of interns, residents, and fellows had experienced some degree of depression, ${ }^{7}$ but doctors have negative attitudes and beliefs about discrimination in relation to mental disorders, ${ }^{8}$ and often attempt to treat themselves. They are also likely to respond late to evident illness in a colleague, and often not until there are obvious issues of professional competence. Depression is the most prominent cause of suicide in any population of doctors. Risk factors for suicide in doctors include younger age, abuse of alcohol and other substances, ${ }^{9}$ recent professional, financial, or personal loss, and access to lethal means of suicide. Women physicians between the ages of 25 and 55 years are nearly four times more likely to kill themselves than most other women. ${ }^{10}$

It may be that doctors are vulnerable to experiencing personal strain and professional impairment because of personal qualities, however in terms of intervention it is worth considering ways in which medical training may compound problems. Personality characteristics related to morbidity for doctors include competitiveness, high expectations of self, rigidity, and excessive concern for detail-the very characteristics which are considered assets in caring for others. ${ }^{10}$ Indeed, there appears to be a triad of "doubt, guilt, and exaggerated sense of responsibility" present in many of those who undertake medical training, with clear implications about vulnerability to the development of psychological difficulties. ${ }^{11}$

When medical students are confronted with suffering and disease they often survive by being emotionally distant, or dehumanising patients.? This is fuelled by the culture of medical training which promotes excessive devotion to work, ${ }^{11}$ despite the adverse personal consequences. ${ }^{12}$ In addition, students are rarely praised but often admonished, and sometimes even abused-ranging from verbal abuse, intimidation, and devaluation to sexual harassment and, less frequently, physical abuse. ${ }^{13}$ Medical students may also witness overtly unethical practices such as patients being hit, verbally abused, and humiliated during ward rounds. ${ }^{14}$ Students question the fairness of being held to professional standards, when faculty do not appear to be held to similarly high standards. ${ }^{15}$

\section{THE NEED FOR ASSESSMENT OF PERSONAL AND PROFESSIONAL DEVELOPMENT: SOME KEY ISSUES}

If these issues are important in the practice of medicine, there is an ethical obligation for 
medical education to promote awareness, prevention, and minimisation of these problems, leading to improved outcomes for doctors, the patients they treat, and the community. However, evaluation of non-cognitive criteria and professionalism in medical students have not received the same attention as evaluation of other aspects of clinical competency, knowledge, and skill. Furthermore, strategies to evaluate professional and unprofessional behaviours in medical schools are not widely developed, published, or evaluated. ${ }^{16}$

Assessment is the mechanism by which medical faculties signal that they value certain subject areas, and lack of formal assessment may undermine the impact of teaching. ${ }^{17}$ Objectives that are not adequately tested are taken less seriously, no matter how important educators and reports say they are. A medical school that fails to conduct such assessment covertly undermines attitudes towards professional and personal development throughout the curriculum.

However, a major difficulty in assessment is the reluctance of physicians to directly confront problem behaviours, often instead responding in ways that avoid moral language. ${ }^{18}$ This failure to directly address underlying attitudes leaves students or junior doctors to misinterpret, undervalue, or entirely fail to notice such subtle feedback. Compounding this issue may be the tendency for students in clinical years to have multiple short rotations, with individual clinical rotations not taking ownership of the professional competency realm.

In addition to assessment, clearly defined processes must be established to deal with unsatisfactory performance, providing the opportunity for active remediation and/or subsequent professional disqualification before graduation, ${ }^{16}{ }^{19}$ a point highlighted by Ratzan ${ }^{20}$ in his review of "Blind Eye: How the Medical Establishment Let a Doctor Get Away with Murder" ${ }^{21}$ which describes a suspected Southern Illinois medical serial killer.

Clinicians who are forced to evaluate the behaviour of others will start to think of their own performance. This may influence education even more than specific courses. ${ }^{1}$

\section{ASSESSMENT OF PROFESSIONAL BEHAVIOUR AND ATTITUDES: CURRENT PRACTICE}

A survey of 135 medical schools in USA and Canada revealed that $54.5 \%$ (of the 88 respondents) have defined, written standards of non-cognitive behaviour. Most frequently included criteria are honesty; professional behaviour; dedication to learning; professional appearance; respect for law and for others; issues of confidentiality, and substance abuse. Eleven respondents (out of 135) indicated that the lack of non-cognitive criteria had led to administrative problems, particularly in the areas of "cheating" and "emotional illness".22

\section{Necessary conditions for assessment of professional behaviour}

If professional behaviours and attitudes are to be assessed with summative consequences, (that is, with the ultimate possibility of withholding students' further education), valid, reliable, and acceptable instruments and procedures are necessary. ${ }^{19}$ It has been advocated that the criteria for assessment be positive, promoting the notion of an ideal physician to which students can aspire, rather than framed in terms of problematic behaviours which are to be avoided. ${ }^{22}$

\section{Timing of assessment}

Most authors stress that assessments should begin at an early stage in the curriculum; the reasons for this include:
- It is difficult to expel students from further studies when they are first informed about their inadequate behaviour in advanced clerkships ${ }^{19}$

- Inadequate professional behaviour is often exhibited during early stages of medical training

- If the inadequate professional behaviour is to be remediated, there needs to be time for this, and for review ${ }^{19}$

- Repeated observations are necessary to assess behaviour as reliably and as objectively as possible ${ }^{1}$

- Serial observations over the longer term are necessary to compensate for the tendency of faculty to avoid giving negative evaluations ${ }^{16}$

- Identified students can potentially be monitored, and placed in clerkship sites that are more highly structured and work with selected faculty who will help the students with their particular professionalism problems. ${ }^{16}$

\section{Assessment strategies in use}

Several medical schools have embarked on the active promotion of professionalism, with varying evaluation methods and varying consequences. Some have developed specific evaluation methods and instruments with consequences similar to those of the evaluation of the academic skills (see below).

\section{Attendance records}

Many medical schools have resorted to superficial means of evaluation, such as noting attendance or participation. This does not focus appropriately on curricular content, exacerbating the perceived differences in importance between these themes and the basic sciences and clinical skills, which are evaluated more objectively and rigorously. ${ }^{23}$

\section{Self and peer assessment}

Students at some schools evaluate themselves and their peers on their professional attitudes and behaviour. ${ }^{24}$ Despite some students feeling uncomfortable about this process, the authors believed that the process helped students to honestly address their strengths and weaknesses. Although accurate self assessment is an important professional characteristic, there is evidence that it is very difficult to achieve, ${ }^{25}{ }^{26}$ others believing that for summative assessment the actual behaviour in the clinical setting should be the focus of assessment. ${ }^{1}$

Other medical schools consider that peer evaluations are a method of reinforcing professional responsibility throughout the full university activities, not just when students know they are being summatively assessed. ${ }^{23}$

\section{Patient evaluations}

Patients are considered by some to be the "gold standard" for assessing the humanistic attributes of the physicians who care for them, ${ }^{27}$ recent research suggesting that in a controlled context, and using aggregated opinions, patients can provide a reliable and valid global opinion which can contribute to the assessment of a student's clinical skills. ${ }^{28}$

\section{Observation of behaviours}

Behavioural observations may include observations by teachers, experts such as psychologists, peers, nursing staff, and simulated patients. The observed behaviours may be actual daily behaviour, videotaped natural behaviour, or behaviour in an explicit examination setting. To reliably assess actual behaviour, repeated observations are necessary, ${ }^{1}$ as well as judgments by different observers. ${ }^{19}$

Nurses' perceptions appear to correlate most closely with those of the patients, ${ }^{27}$ suggesting that nurses' evaluations 
could supplement those of patients to obtain more reliable assessments.

\section{Student journals}

Some medical schools base assessment on a combination of journal entries by students containing reactions and readings to set topics, the quality of class discussion, and essay examinations. ${ }^{23}$

\section{Psychological tests}

Psychological tests designed to measure maturity, responsibility, self control, tolerance, self acceptance, and flexibility have been suggested as a means of evaluating students. Questionnaires measuring changes in attitudes towards psychosocial aspects of medicine, tolerance of ambiguity, empathy, wellbeing, stress and burnout, and self esteem have also been suggested as a means of evaluating students. ${ }^{2}$

\section{Structured examinations}

In Australia, at the University of Newcastle, the theme of health law and ethics was assessed by means of the modified essay question (MEQ), designed to evaluate student sensitivity to ethical issues and the ability to critically and ethically reflect and justify. ${ }^{29}$ The strength of this assessment was felt to be its objectivity, efficiency, and logistical feasibility, the limitation being that although it assesses what the student knows, it fails to assess what the student can do or does do. Hence in 1992, the OSCE (Objective Structured Clinical Examination) was introduced, including a "long case" assessment, to directly assess professional values and attitudes, and interaction skills. These additional methods do not necessarily possess predictive validity for ethically or clinically appropriate behaviour in the unobserved work context. $^{29}$

\section{The development of specific processes and assessment instruments}

Published literature describes in varying detail the processes and assessment instruments used in different medical schools. ${ }^{1}{ }^{16193031}$ Table 1 summarises the non-cognitive evaluation strategies of these international medical schools and table 2 describes the non-cognitive themes assessed by these same medical schools.

Key assessment themes across institutions include:

- How the student relates to other persons (peers, staff, patients)
- The ability of the student to be self reflective

- Communication skills

- The demonstration of qualities such as empathy, respect for others, responsibility, active and efficient task performance.

Interestingly, the promotion of self care does not appear to be a prominent theme.

\section{The University of California}

The most comprehensive review of an assessment process is from the University of California, San Francisco School of Medicine, describing the first four years (1995-98) of an evaluation system. ${ }^{16}$ Students in all clinical years are assessed during each rotation, rating knowledge, clinical skills, and interpersonal skills on a scale from $1-4$, covering "excellent", "solid", "concern", or "problem". (This represents an expansion of an existing assessment.) A "concern" or "problem" rating in interpersonal skills prompts submission of a Physicianship Evaluation Form, which in turn triggers a school review of the student.

\section{Reports of unprofessional behaviour}

In the above report, from 1995-98, 29 reports of unprofessional behaviour were submitted to the Dean's office, concerning 24 students. Problems most often cited were unmet professional responsibility, unsatisfactory relationships with members of the health team, resistance to change or criticism, arrogance, and inadequate rapport with patients. No comments regarding underlying physical or emotional problems were noted; however, several students were referred to the school's counselling service following meetings with the medical school Dean. All but one of the students graduated, although four had their difficulties cited in the Dean's letter of recommendation for residency. One student who had a pattern of interpersonal difficulties voluntarily withdrew from medical school.

\section{Difficulties experienced}

An ongoing issue is the disparity of reporting patterns between physicians from different clinical disciplines. Although it is possible that unprofessional behaviour is more likely to occur in some clerkships than others, it is more probable that different disciplines value different aspects of professionalism. For example, communication skills may be more highly regarded in some disciplines than in others.

Table 1 Published non-cognitive assessments

\begin{tabular}{|c|c|c|c|c|c|c|c|c|c|}
\hline Medical School & $\begin{array}{l}\text { Year } \\
\text { introduced }\end{array}$ & $\begin{array}{l}\text { Written } \\
\text { criteria }\end{array}$ & $\begin{array}{l}\text { Assessment } \\
\text { methods }\end{array}$ & Year of course & $\begin{array}{l}\text { Formative/ } \\
\text { summative }\end{array}$ & Assessors & Logistical problems & $\begin{array}{l}\text { Mechanism } \\
\text { for fail }\end{array}$ & $\begin{array}{l}\text { Past admin/ } \\
\text { legal } \\
\text { problems }\end{array}$ \\
\hline Amsterdam ${ }^{\prime}$ & 1998 & Yes & $\begin{array}{l}\text { Videotaped } \\
\text { history taking; } \\
\text { specific tool }\end{array}$ & Clinical & Both & $\begin{array}{l}\text { Clinicians; nurses; } \\
\text { medical psychology }\end{array}$ & NS & Yes & NS \\
\hline Maastricht $^{19}$ & & Yes & $\begin{array}{l}\text { Simulated } \\
\text { patient IV; } \\
\text { specific tool }\end{array}$ & All & Both & $\begin{array}{l}\text { Clinicians; } \\
\text { preclinical teachers }\end{array}$ & Admin burden & Yes & NS \\
\hline San Francisco ${ }^{16}$ & 1995 & Yes & Specific tool & $\begin{array}{l}\text { Clinical; future } \\
\text { to include } \\
\text { preclinical }\end{array}$ & Summative & Faculty clinicians & \multicolumn{2}{|l|}{$\begin{array}{l}\text { Time constraints; student } \\
\text { concerns re fairness; } \\
\text { notification in student } \\
\text { files; faculty acceptance }\end{array}$} & \\
\hline New Mexico ${ }^{31}$ & 1987 & NS & Specific tool & All & $\begin{array}{l}\text { Incident } \\
\text { related only }\end{array}$ & $\begin{array}{l}\text { Science faculty; } \\
\text { faculty clinicians; } \\
\text { admin staff }\end{array}$ & NS & $\begin{array}{l}\text { Potential, but } \\
\text { not formal } \\
\text { plan or } \\
\text { structure }\end{array}$ & \\
\hline McMaster ${ }^{30}$ & 1984 & Yes & Specific tool & All & Summative & NS & $\begin{array}{l}\text { Legal appeals; reluctance } \\
\text { by tutors to give negative } \\
\text { reports }\end{array}$ & Yes & NS \\
\hline
\end{tabular}


Table 2 Published international medical schools' non-cognitive themes assessed

\begin{tabular}{|c|c|c|c|c|c|c|c|c|c|c|c|}
\hline Medical school & $\begin{array}{l}\text { Ethical } \\
\text { behaviour }\end{array}$ & Teamwork & $\begin{array}{l}\text { Communication } \\
\text { skills }\end{array}$ & $\begin{array}{l}\text { Self } \\
\text { reflection }\end{array}$ & $\begin{array}{l}\text { Self } \\
\text { care }\end{array}$ & $\begin{array}{l}\text { Empathy/ } \\
\text { respect }\end{array}$ & $\begin{array}{l}\text { Inappropriate } \\
\text { IT use }\end{array}$ & $\begin{array}{l}\text { Self directed } \\
\text { learning }\end{array}$ & $\begin{array}{l}\text { TTask } \\
\text { performance }\end{array}$ & Appearance & e Responsibility \\
\hline Amsterdam ${ }^{\prime}$ & Yes & Yes & Yes & Yes & & Yes & & & Yes & & Yes \\
\hline Maastricht $^{19}$ & & Yes & Yes & Yes & & Yes & & Yes & Yes & Yes & Yes \\
\hline San Francisco ${ }^{16}$ & Yes & Yes & Yes & Yes & & Yes & & & Yes & & Yes \\
\hline New Mexico ${ }^{31}$ & Yes & & Yes & Yes & Yes & Yes & & & Yes & & Yes \\
\hline McMaster $^{30}$ & & & Yes & Yes & & Yes & & & & & Yes \\
\hline
\end{tabular}

Students' apparent professionalism problems may also sometimes be the result of a dysfunctional team. ${ }^{16}$

\section{Support from students}

Student support for the evaluation system appears to be a critical factor in its adoption, and student input is invaluable in refining assessment processes. A year after the above implementation, a student/faculty liaison committee recommended documentation on the evaluation form indicating student agreement or disagreement with the evaluation, the student's signature, and documentation that the student had been counselled by the clerkship director completing the form. ${ }^{16}$

\section{Concerns from faculty}

Confronting students, making written reports and dealing with the consequences of that report are clearly difficult for faculty, ${ }^{16}$ who are often unsure about the accuracy of their perceptions. In the preclinical faculty, tutors felt they had inadequate contact with students to evaluate their professionalism, and that they were not qualified to evaluate students' physicianship skills.

\section{Impact on professionalism}

University of California graduates have undergone evaluation of academic skills, attitudes, and behaviours on completion of their first and sometimes second and third postgraduate years. One of the most common reasons for graduates to fail residency is "attitudes". When honesty, integrity, or personality faults were identified and remediation unsuccessful, the resident was dismissed. ${ }^{16}$ It is unclear if the number of unsatisfactory graduates decreased after the formal development and assessment of professionalism began in 1995 .

\section{LITIGATION ISSUES}

One of the postulated reasons that formal evaluation of noncognitive skills has not been readily undertaken by medical schools and accepted by clinicians is the fear of litigation.

A review of litigation issues found that "candid evaluations of student performance will be protected if they are good faith exercises of professional judgment, not communicated to third persons without a need to know, and not made with malicious intent". Furthermore, the courts found that "faculty members were protected by an absolute privilege because there was an implied consent on the part of the student who seeks an academic credential to have the evaluations used within the school". ${ }^{32} 33$

Courts have upheld medical schools' rights to establish both cognitive and non-cognitive academic requirements for graduation, and have upheld student dismissals for failure to meet these requirements. Faculty should document performance problems candidly and in detail, clearly separate factual observations from interpretations, and not retreat even in the face of threatened litigation..$^{32}{ }^{33}$ The use of clearly defined criteria, and rating scales delineating the requisite knowledge, skills, and professional characteristics are considered useful to provide more objective criteria for such evaluations.

Student review committees should act early to identify marginal and failing students, give notice to them of their deficiencies and the consequences if not rectified, provide access to students of their evaluations, and provide assistance where possible. A further recommendation is that legal counsel be consulted during new developments or reviews of such policies and procedures to ensure they meet due process procedural requirements. ${ }^{33}$

An issue not addressed in the literature is the ethical duty of medical schools and faculty to evaluate professionalism skills and to develop procedures for dealing with inadequate or unsatisfactory performance.

\section{ETHICAL AND OTHER CONTROVERSIAL ASPECTS}

Some of the concerns raised about the assessment of ethical and professional behaviour follow.

\section{Lack of objectivity}

There is a widespread belief that the non-cognitive areas cannot be evaluated objectively. Assessing behaviour inevitably involves an exercise of judgment, which many believe makes professional behaviour assessment too difficult and unpredictable; however the fact that human judgment is necessary for the assessment of professional behaviour, cannot alone explain why this kind of assessment ought not occur. ${ }^{34}$

There is potential for bias in assessment, including sex and racial biases. ${ }^{35}$ Assessing professional behaviour after more prolonged contact rather than on a cross sectional interview may reduce, but not eliminate such bias.

\section{Validity issues}

A study of the validity and importance of low ratings given to medical graduates in non-cognitive areas found that low ratings on professional attitudes were more important than low ratings on knowledge, data gathering skills, and clinical judgment in relation to the offer of further residency training. ${ }^{36}$ Substantial correlations were shown between the residency offer and medical school ratings for graduates with high and low ratings in the non-cognitive areas. The study found strong relationships between performance in noncognitive aspects of patient care during medical school, and that during the first postgraduate year, especially for graduates with the highest and lowest ratings. ${ }^{36}$

\section{Individuality issues}

It is difficult and some say questionable to assess the beliefs, feelings, and intentions of medical students and, further, assessment implies the imposition of norms-potentially crossing borders of freedom of thought and individuality. ${ }^{1}$

\section{Administrative burden}

Assessment and registration of professional behaviour has significant administrative implications. There is need for a balance between the amount of information gathered about a 
student's professional behaviour in order to make a valid judgment, and the amount that is burdensome for administration. ${ }^{19}$

It is unclear whether information should be gathered about the behaviour of some or all students. The University of New Mexico evaluated students on an incident related basis. ${ }^{31}$ Others argue that judgments should be made on all students-however, the administrative burden is enormous. ${ }^{19}$

\section{Cultural issues}

With increasing cultural diversity among students and patients, there is potential for clashes of values. However it can be argued that defining professional standards is acceptable, given that the ethical and moral values evaluated are basic, and transcend most cultural differences. ${ }^{16}$

\section{Confidentiality}

The available literature fails to substantially address this issue, although some medical schools have grappled with confidentiality aspects. Some believe that the dissemination of confidential information should only be undertaken with the permission of the student. ${ }^{19}$ At one school, it was agreed that an entry would be made in their file only after two or more clerkship reports of unprofessional behaviour. ${ }^{16}$

\section{DISCUSSION}

The community wants doctors who are clinically skilful, who behave in an ethical and professional manner, and a profession which is accountable and acts responsibly towards both patients who are dependent on it and towards doctors who practice within it. There is evidence that medical schools are showing a trend towards a focus on professional behaviour, attitudes, and personal development, and the development of assessment processes which reflect this priority.

A major concern must remain the evidence from the literature about the paucity of attention to self care and the health and wellbeing of medical students and young doctors. In the area of drug and alcohol use, for example, there is potential for medical schools to discourage inappropriate use of alcohol at social functions, and to actively introduce structured programmes on alcohol and drugs, specifically aimed at the needs of students. ${ }^{37}$

In attempting to promote ideal behaviour and respond to problem behaviours, a broad approach is needed, which encompasses self reflection and attention to personal health and wellbeing. It is not intuitive for students to consider these issues, and they require support in understanding the need for exploration of personal ideas and experiences, preferably facilitated by a tutor with "good interpersonal skills who holds a high regard for students as people".38 Given funding concerns within education, and erosion of staff numbers and resources, this ideal may be difficult to achieve. More critically, this broad approach is at odds with the emphasis on evidence based medicine: "When medical students are taught, explicitly and implicitly that the only true medical knowledge comes from empirical, objective, quantitative enquiry, they naturally distrust all knowledge that is gained from other methods" ${ }^{39}$ It may also be hard work "To convince hard-headed colleagues that ethics, professionalism, and humanism are not just hair-spray for the already fuzzy-headed, but go to the heart of the practice of medicine" ${ }^{40}$

The teaching of professional issues is difficult, and assessment complex. The burning question is whether assessment of professional behaviour has predictive value for the practice of medicine as a postgraduate. The answer is unclear. Those insidious boundary crossings which may herald descent on the "slippery slope" to more destructive violations of the doctor-patient relationship may go undetected by current assessment measures. Similarly, mood disturbance or substance abuse may remain covert until significant impairment is readily apparent. At the very least, prospective assessment of student performance would be required, comparing performance results with subsequent professional conduct. If the medical profession wants to retain its "internal morality" and produce a meaningful commitment to upholding the standards of care which the profession is entrusted to generate, ${ }^{34}$ academic rigour will need to be applied to the teaching, assessment, and ongoing promotion of the ethical and professional conduct of medical students.

\section{Authors' affiliations}

K Boon, Royal Brisbane Hospital, Herston, Australia

J Turner, Department of Psychiatry, University of Queensland, Australia

Sources of support: none

Disclaimers: none

\section{REFERENCES}

1 TenCate, Th J, De Haes JCJM, et al. Summative assessment of medical students in the affective domain. Medical Teacher 2000;22:40-3.

2 Novack DH, Epstein RM, Paulsen RH. Toward creating physician healers: fostering medical students' self awareness, personal growth and well-being. Acad Med 1999;74:516-20.

3 Boisaubin EV, Levine RE. Identifying and assisting the impaired physician. Am J Med Sci 2001;322:31-6.

4 Galletly CA. Psychiatrist-patient sexual relationships: the ethical dilemmas. Aust N Z J Psychiatry 1993;27:133-9.

5 Lawrence JM. The impaired doctor. Med J Aust 1992;157:4-6.

6 Lawrence JM. Alcoholic doctors. The Healthy Doctor 1999;2:1-2.

7 Phillips J. The Harry Harris oration. Urological Society of Australia. Newsletter 1996 Summer: $11-15$

8 Jorm AF, Korten AE, Jacomb PA, et al. Attitudes towards people with a mental disorder: a survey of the Australian public and health professionals. Aust N Z J Psychiatry 1999;33:77-83.

9 Kelly B, Varghese F. The emotional hazards of medical practice. In: Sanders MR, Mitchell C, Byrne GJA, eds. Medical consultation skills. Australia: Addison-Wesley, 1997:472-88.

10 Roeske NCA. Risk factors: predictable hazards of a health career. In: Scott CD, Hawk J, eds. Heal thyself: the health of health care professionals. New York: Brunner/Mazel Inc, 1986:56-70.

11 Gabbard GO. The role of compulsiveness in the normal physician. JAMA 1985;254:2926-9.

12 Coombs RH, Fawzy FI. The impaired-physician syndrome: a developmental perspective. In: Scott CD, Hawk J, eds. Heal thyself: the health of health care professionals. New York: Brunner/Mazel Inc, 1986:44-55.

13 Sheehan M, Sheehan DV, White K, et al. A pilot study of medical student 'abuse' student perceptions of mistreatment and misconduct in medical school. JAMA 1990;263:533-7.

14 Kozlowska K, Nunn K, Cousens P. Adverse experiences in psychiatric training. Part 2. Aust N Z J Psychiatry 1997;31:641-52.

15 Bickel J. Medical students' professional ethics: defining the problems and developing resources. Acad Med 1991;66:726-9.

16 Papadakis MA, Osborn EHS, Cooke M, et al. A strategy for the detection and evaluation of unprofessional behaviour in medical students. Acad Med 1999;74:980-90.

17 Goldie J, Schwartz L, McConnachie A, et al. The impact of three years' ethics teaching, in an integrated medical curriculum, on students' proposed behaviour on meeting ethical dilemmas. Med Educ 2002;36:489-97.

18 Burack JH, Irby DM, Carline JD, et al. Teaching compassion and respect. Attending physicians' responses to problematic behaviours. J Gen Intern Med 1999; 14:49-55.

19 Van Luijk SJ, Smeets JGE, Wolfhagen I, et al. Assessing professional behaviour and the role of academic advice at the Maastricht Medical School. Medical Teacher 2000;22:68-172.

20 Ratzan RM. Blind eye: how the medical establishment let a doctor get away with murder by James B Stewart [book review]. N Engl J Med 2000;342:14.

21 Stewart JB. Blind eye: how the medical establishment let a doctor get away with murder. New York: Simon and Schuster, Stewart, 1999.

22 Miller GD, Frank D, Franks RD, et al. Noncognitive criteria for assessing students in North American medical schools. Acad Med 1989;42:42-5.

23 Makoul G, Curry RH, Novack DH. The future of medical school courses in professional skills and perspectives. Acad Med 1998;73:48-51.

24 Asch E, Saltzberg D, Kaiser S. Reinforcement of self-directed learning and the development of professional attitudes through peer- and self-assesment. Acad Med 1998;73:575.

25 Gordon MJ. A review of the validity and accuracy of self-assessment in health professions training. Acad Med 1991;66:662-79.

26 Gordon MJ. Self assessment programs and their implications for health professions training. Acad Med 1992;67:672-9. 
27 Woollicroft JO, Howell JD, Patel BP, et al. Resident-patient interactions: the humanistic qualities of internal medicine residents assessed by patients, attending physicians, program supervisors and nurses. Acad Med 1994;69:216-24

28 Wilkinson TJ, Fontaine S. Patients' global rating of student competence. Unreliable contamination or gold standard? Med Educ 2002;36:1117-21.

29 Mitchell KR, Myser C, Kerridge IH. Assessing the clinical ethical competence of undergraduate medical students. J Med Ethics 1993;19:230-6.

30 Blake JM, Norman GR, Smith EKM. Report card from McMaster: student evaluation at a problem-based medical school. Lancet 1995;345:899-901.

31 Phelan S, Obenshain S, Galey WR. Evaluation of the noncognitive professional traits of medical students. Acad Med 1993;68:799-803.

32 Irby DM, Fantel Jl, Milam SD, et al. Legal guidelines for evaluating and dismissing medical students. N Engl J Med 1981;304:180-4.

33 Irby DM, Milam S. The legal context for evaluating and dismissing medical students and residents. Acad Med 1989;64:639-43.
34 Parker M. Assessing medical students' professional development and behaviour: a theoretical foundation. Focus on Health Professional Education: A Multi-Disciplinary Journal 2000;2:28-38.

35 Shaw D, Martz DM, Lancaster CJ, et al. Influence of medical school applicants' demographic and cognitive characteristics on interviewers' ratings of noncognitive traits. Acad Med 1995;70:532-6.

36 Herman MW, Veloski JJ, Hojat M. Validity and importance of low ratings given medical graduates in noncognitive areas. J Med Educ 1983:58:837-43.

37 Wallace P. Medical students, drugs and alcohol: time for medical schools to take the issue seriously. Med Educ 2000;34:86-7.

38 Howe A. Professional development in undergraduate medical curricula-the key to the door of a new culture? Med Educ 2002;36:353-9.

39 Wear D, Castellani B, The development of professionalism: curriculum matters. Acad Med 2000;75:602-11.

40 Bickel J. Proceedings of the AAMC conference on students' and residents' ethical and professional development. Acad Med 1996;71:62. 